Journal of Engineering and Applied Sciences 15 (2): 714-729, 2020

ISSN: 1816-949X

(C) Medwell Journals, 2020

\title{
Re-Engineering University Performance: Antecedents and Mediating Variables
}

\author{
${ }^{1}$ Bandar Abdulla F.H. Alharthi, ${ }^{2}$ Gamal S.A. Khalifa, ${ }^{3}$ Abuelhassan E. Abuelhassan, \\ ${ }^{1}$ Osama Isaac and ${ }^{1}$ Ahmed H. Al-Shibami \\ ${ }^{1}$ Department of Management, Faculty of Business and Accountancy, \\ ${ }^{2}$ Department of Hospitality Management, Faculty of Hospitality and Tourism, \\ Lincoln University College, Selangor, Malaysia \\ ${ }^{3}$ Department of Hotel Management, Institute of Tourism and Hotels, \\ Ministry of Higher Education, Qena, Egypt
}

\begin{abstract}
The aim of the study is to re-engineer the relationship among Strategic Planning (SP), Innovation (INN), Employee Strategic Alignment (ESA) and University Operational Performance (UOP). Survey-based procedures and the self-administrative questionnaire have used to collect data from the university academic staff. The questionnaire was used in five points Likert scale. About 500 questionnaires distributed were 309 valid returned. The findings of the study have investigated the relationship between strategic planning and university operational performance through innovation and employee strategic alignment. The proposed hypothesis have supported in order to consist of all the variables relationships. This study has an essential influence of UAE universities that imply the actual theory of strategic planning for university perspectives that increase the operational performance in the university future familiarity and standard operation. The data were gathered from single respondents which might result in possible response bias sometimes that indicates the limitation. This study outcome has preferred or suggested for implementation for the managerial thinking for future bitterness of the organization.
\end{abstract}

Key words: Strategic planning, employee strategic alignment, innovation, university performance, UAE, familiarity

\section{INTRODUCTION}

The new higher education systems have developed speedily with the standard and worldwide quality. Latorre-Medina and Blanco-Encomienda (2013) argued that throughout the previous decade the educational systems have endured long reformation and transformation processes from an old fashioned educational management model that deeply seated in the past to astrategic model (Agwa et al., 2018; Hussein et al., 2013). To analyze educational operations, the model fundamentally connects the service provided by the university to the resources consumed in providing a common view of university educational operations. According to the researcher's knowledge, there were not many current studies focused on UAE higher education and handled the area of university operational performance (Albadry, 2015).

In addition (Borman and Motowidlo, 1993; Tangen, 2003) have explained regarding interrelationships in their model of the classical approach to operational performance. It indicates a number of multi-faceted appropriations between six performance criteria: effectiveness, efficiency, quality, productivity, innovation and profitability (Mohamed et al., 2018; Rolstadas, 1998). It is an essential issue in learning and management fields. It is through participation and commitment you will get good feedback from the employees (Adi and Pulos, 1980). Therefore, it is necessary to achieve the best operational performance among employees which will be achieved only by providing a good working environment and selection process, continuous planning, training and development and physical and moral motivation either through financial rewards or through promotion (Johnes, 1996; Williams, 1988). This study has stated about the university operational performance as a dependent variable that indicates the services of the students and academic-related administrative tasks. Most significantly, this type of performance tires the institutional reputation and global familiarity (Qoura and Khalifa, 2016).

Strategic planning depends on the idea that the need for planning is necessary or not and whether external or environmental conditions influence the output 
of the strategy (Radomska, 2014). Accordingly, strategic planning is remarkable importance in terms of new service strategies because of any new service depends on how the organization establishes and implements its own rational plan (Borrego and Henderson, 2014; Kruss et al., 2015; Leigh and Blakely, 2016). This study focuses on strategic planning in order to adopt the institutional strategies that direct the road map of getting future achievements.

Furthermore, the innovation includes the organization conditions and process related to the basic work activities by integrating social and technical new concepts and ideas (Drucker, 2014). It indicates all about the organizational systematic, technological and advanced ideas that create more innovative in the competitive market (Abd-Elaziz et al., 2015; Abou-Shouk and Khalifa, 2017; Shamsi et al., 2018; Khalifa and Fawzy, 2017; Khalifa and Hewedi, 2016; Khalifa and Mewad, 2017). Specifically, in the university context, the innovation implies on creating a new program, a system for enrolment, current student verification, program development using access and technology (Prager and Omenn, 1980; Conway and Steward, 2009). Moreover, employees should be more conscious to achieve greater steadiness and alignment in organizational strategies (Abou-Shouk et al., 2014; Abou-Shouk and Khalifa, 2017; Henderson and Venkatraman, 1999; Khadem, 2008). Organizations are trying to increase their competitiveness, adopt employee alignment as a large-scale strategic tool (Gagnon and Judd, 2003). The process of transferring objectives to employees, the participation of mid-level managers in the strategic planning process, the acquisition of strategic knowledge are examples of employee's alignment (Beehr et al., 2009). The current study aims to investigate the casual relationship between SP and UOP via. employee strategic alignment and innovation.

\section{Literature review}

Strategic planning: Strategic planning requires explicit action to set specific long-term objectives and generate alternative strategies, requiring rigorous implementation and a system of results control (Kezar et al., 2015). It identifies the objectives of an organization, highlights the threats and competitive opportunities that it may face, controls and implements the procedures, assists in strategically important organizational decision-making which ultimately strengthens the performance of that organization (Ackoff, 1970; Menon et al., 1999). According to the various studies that have addressed the development of new strategies that adopting certain planning steps by companies reflected positively on their product development cycles as they have become faster (Hult et al., 2006; Montoya-Weiss and Calantone, 1994).
Brown and Eisenhardt (1995), Jimenez-Jimenez and Sanz-Valle (2011) stated that the planning provides the official plan carefully designed in all its details and tactics to ensure the successful implementation of the strategy. It helps in solving organizational disputes and leads to provide a clear vision which works to accelerate the mission development on the one hand and enhance the performance of the organization (Kettunen, 2006; Mohamed et al., 2019; Montoya-Weiss and Calantone (1994). Peterson et al. (2011) have mentioned that providing the distinctive features of effective strategic management and enhancing strategic planning in terms of quality, speed and productivity results from the adoption of planning based on sound market research followed by implementation and formalization consistent with that plan (Bason, 2018; Khalifa and Abou-Shouk, 2014). In this study, the strategic planning influences in direct and indirect effect (innovation and strategic alignment) on university operational performance. Basically, university operational learning consists of the services and operation related to the student's service and employee administrative tasks. Consequently, the strategic planning depends on the future plan of the chart that going to be achieved for the organization. In order to direct effect of strategic planning on university operational performance indicates that strategic planning can increase the operational performance of the university (Shrader et al., 1984). The mediating roles of innovation and strategic alignments between strategic planning and university operational performance imply the strong relationship between both variables in terms of enhancing the administrative performance of the university. To the best of researchers knowledge, the mediation of two variables between strategic planning and university operational performance is the first attempt to investigate the indirect relationship. According to the above discussion and research-based view, the researcher comes to these hypothesis:

- $\mathrm{H}_{1}$ : SP has a positive effect on UOP in UAE

- $\mathrm{H}_{2}$ : SP has a positive effect on innovation in UAE universities

Employee strategic alignment: Many researchers pointed out that the improvement of internal communication in organizations can be due to strategic alignment process (Bason, 2018; Shrader et al., 1984). Spee and Jarzabkowski (2011) have emphasized the strategic alignment process seeking to strengthen communication within organizations. Langly (1988) added that creating an information network that promotes communication and discussion of strategic questions is one of the key roles of the strategic alignment process. Accordingly, employees should be given more attention 
to achieve greater consistency and alignment with their organization and its strategies as it is considered the main source of its organizational success (Barney, 1991). In the area of strategic management, the alignment of staff is an important concept as it is the key that achieves the organizational goals and leads to the strategic success (O’Reilly et al., 2010). In addition, employees understanding of the organization's strategy and the role they have to play in doing so, partly affects employee compliance with the organizational strategy (Boswell and Boudreau, 2001).

Further, employee agreement and understanding of their organization's strategy is one of the challenges facing employee alignment (Khadem, 2008). Beehr et al. (2009) emphasized that the good employee's understanding of the strategy of their organization will help them to take appropriate actions and behaviors that are in line with the interests and needs of the organization in order to achieve strategy which will eventually transform organizational objectives into tangible results (Boswell and Boudreau, 2001). Accordingly, achieving full acceptance of the staff and true alignment with the organizational strategy emerges as a result of the convergence of organizational and individual objectives. Allowing intermediate managers to participate in the strategy process helps to bring the goals closer and facilitates the implementation of the strategy at the same time (Ketokivi and Castaner, 2004; Wooldridge and Floyd, 1990). Moreover, the employee strategic alignment has a direct influence on university operational performance that makes a sense of employee internal individual and grouped communication. There are little studies has been mentioned this relationship in the literature but the mediating role of it plays a unique connection between strategic planning and university operational performance. Depending on the above considerations with regard to the role of strategic alignment to improve the three precedents of university operational performance, the study assumes the following hypothesis:

- $\mathrm{H}_{3}$ : SP has a positive impact on ESA

- $\mathrm{H}_{4}$ : ESA has a positive impact on UOP

- $\mathrm{H}_{6}$ : ESA have mediating influence between SP and UOP

Innovation: The Resource-Based Theory (RBT) has been used by many theoretical studies as a theoretical mean to demonstrate the competitive value of innovation in terms of performance (Prajogo, 2016; Saunila et al., 2014). According to his point of view, Saunila et al. (2014) considered innovation as an important factor in the company's performance (Mohamed et al., 2019; Qoura and Khalifa, 2016). Prajogo (2016) emphasized that organizational performance can be improved through the different types of innovation as technical, managerial, etc. because innovation is one of the most effective competitive strategies used in business markets that helps create competitive advantage and ensures its sustainability (Chen and Huang, 2010; Shamsi et al., 2018).

Meanwhile, it has been identified at a various levels such as micro, macro and project level. In some disciplines explain innovation such as productivity based, service-based, activities based and technologybased (Berry and Berry, 2007). In this study we combining the service, activities and technology-based innovation in the organization (Acemoglu et al., 2018). Consequently, the broad definition as activities that involve substantial novelty for the adopting administration but it's not required to the new world. Accordingly, it indicates the new approach to designing, ideas implementing, marketing goods that provides to the innovator or his organization and generation of new thinking into a new process and services (Badran and Khalifa, 2016; Dodgson, 2018; Khalefa, 2015; Urabe et al., 2018). Lusch and Nambisan (2015) defined that innovation is the newly assimilated knowledge of employment which can be simplified and explained by various considerations (Woodside and Biemans, 2005) that concern in sense of commercialization and developing systemize technological facilities (Adams et al., 2006). In addition, innovation has a direct influence on university operational performance which indicates that increasing innovation operational performance will be increased. There are several studies have investigated related to innovation and performance but specifically for the university operational performance conduct very little studies in the literature. Furthermore, the mediation effect plays an important role for both of variables relationships. As a result, managers should identify and manage innovations in order to enhance their operational performance because the overall performance of the organization is positively related to established innovations. Thus, the following proposed hypothesis is based on the previous literature:
- $\mathrm{H}_{5}$ : innovation has a positive impact on UAE universities' UOP
- $\mathrm{H}_{7}$ : innovation has a mediating effect on the relationship between SP and UOP

University operational performance: A necessity to any organization for running or sustain in the market would be operational performance (Shamsi et al., 2018; Feng et al., 2018; Isaac et al., 2016; Nusari et al., 2018) and it should maintain appropriately. This occurs because it plays a significant role in ensuring all policies and procedures within the organization with its objectives 
and goals (Shamsi et al., 2018; Mohamed et al., 2018). Through a well-defined and functional operations management system, an organization has more of an advantage to better meet their needs while also meeting their own goals and objectives (Croom et al., 2018; Valdez, 2017). In addition, operational performance comes with many benefits that a university can use to its advantage. It has been used to refer to internal quality results and external quality results, respectively (Khalifa and Abou-Shouk, 2014; Uluskan et al., 2017). Utilizing the various tools with this and also contributes to the ability to properly encourage, implement and monitor performance (Alkhateri et al., 2018; Khalefa, 2015). Understanding how technology and other services are necessary to see results with operational performance (Inman et al., 2011; Khalifa and Mewad, 2017).

Furthermore, performance is measured at the organizational level to see whether objective methods or subjective methods should be adopted (Celine et al., 2009). On the one hand, the most common objective methods used to gain vital such as profit levels of organizations (Lannelongue et al., 2015) but subjective approaches define operational performance depending on organizational attitudes. Antony and Bhattacharyya, (2010) stated the productivity is an aspect of operational performance (Mohamed et al., 2018, 2019). However, university operational performance plays an essential role in this study as of dependent variable in order to interrelate with strategic planning. Accordingly, employee strategic alignment and innovation also mediates between strategic planning and university operational performance (Isaac et al., 2016; Jansen et al., 2006; Luo and Park, 2001). The overall model of the study its self is a theoretical contribution and relationship based-variables also indicates contributions to university operational performance. To the best of researchers knowledge, this study has not investigated in the literature unless some of the relations clarified according to contextual consideration.

\section{MATERIALS AND METHODS}

Research design and measurements: This study is followed the quantitative approach that collections out the quantify data in order to use statistics for analyzing data set (Malhotra et al., 2004). Moreover, this research approach has successfully been used in the context of operational performance studies, especially in the universities background (Bowen and Shoemaker, 2003). Information about respondent's beliefs, motives and attitudes provides by an effective survey design in the study field in the case of research, measure the perceptions of universities staffs. Therefore, this study needs a self-administrative questionnaire for assuming the responsibility of employee reading and responding to the questions. The researcher can distribute numerous questionnaires to different respondents in different places simultaneously by using a self-administrated questionnaire. This study's constructs have adapted for the previous literature and used five-point Likert scale following strongly disagree (1) strongly agree (5). Therefore, the construct strategic planning has adapted form (Albadry, 2016; Galbreath, 2010), innovation from (Aragon-Correa et al., 2007; Garcia-Morales et al., 2012), employee strategic alignment from (Ouakouak and Ouedraogo, 2013) and university operational performance from (Garcia-Morales et al., 2012). For this study, the hypothesized variables and their relationships in the model have been derived from the available literature of the models and theories that have been prescribed in the literature mentioned above. The proposed model can be in Fig. 1. While examining the proposed model.

Data collection and sampling: Data for this study were collected from a self-administered survey that was circulated in UAE universities. A survey instrument was developed to explore the impact of UOP and SP, I and ESA. The questionnaire was pre-tested several times to ensure that wording, format and sequencing of questions were appropriate. This research applies a survey-based methodology for gathering data which has many advantages that mainly suitable for this study. Kleinberg et al. (1999) explained that survey-based methods give advantages for assembling a large amount of data about an individual respondent at one time and its flexible for collecting data. Accordingly, in the quantitative research approach of study survey-based methods can collect a large number of data sample quickly and efficiently (Hair et al., 2006). This study sample size is decided in consideration of the following researcher connection. Flynn and Pearcy (2001) mentioned that an acceptable sample size with no simple and definitive rule an accurate sample size which considerable debate in the research field. The questionnaire was distributed among the university academic staffs within the organization and 500 questionnaires distributed were 309 valid questionnaires collected. The procedures of collecting data were contacted to the top management to collect data and conduct survey with the academic staff. For the analysis of the research model using PLS (Partial Least Square) in order to input data in SPSS. It needs a large sample which is less stable for estimation purpose, some researchers believe that PLS may use for sample size as small as 50 and large 5000 (Hulland, 1999). This study was used PLS for analysis technique in order to get the result for path, estimation and supported the hypothesis. 


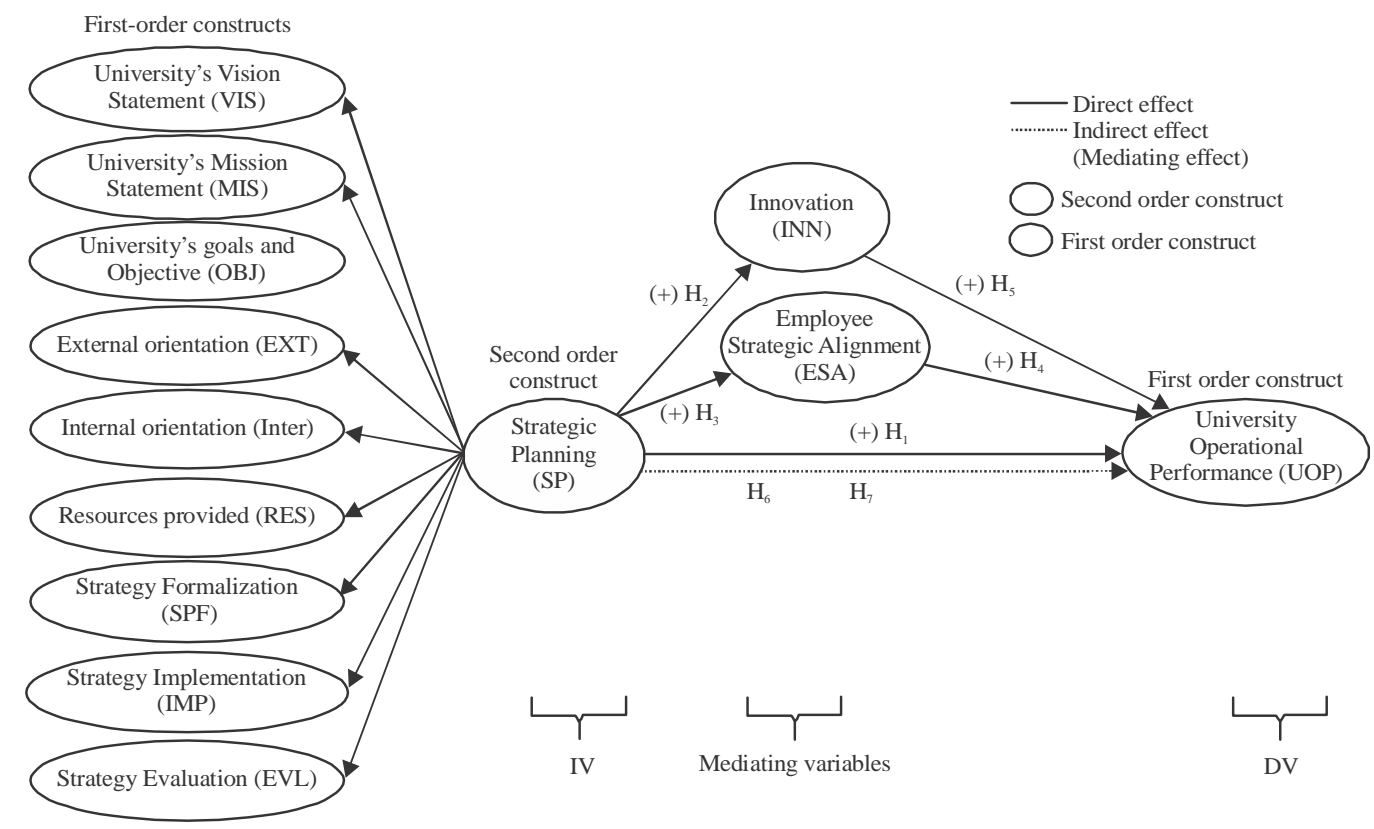

Fig. 1: The conceptual model

\section{RESULTS AND DISCUSSION}

Descriptive analysis: The researcher distributed 500 questioners to the Academic staff in UAE's educational institutions, the valid questionnaires were received by the researcher are 309 questionnaires by responding rate is $61.8 \%$. The responding sample $(\mathrm{n}=309)$ consisted of $62.5 \%$ male and $37.5 \%$ female employees. Most of the participants were aged between 30-39 years this accounted for $41.7 \%$ of the responses followed by the age range of $<30$ years at $30.7 \%$ of total responses. With regards to the academic positions of selected participants, 54.4 of participants were assistant professors, $26.5 \%$ were associate professors and all other categories had nearly the same number of participants. Close to $25.3 \%$ of the respondent's working experience were $<5$ years followed by the experience range of $11-15$ years at $23.6 \%$ of total responses. A total of 71 , accounting for $22.98 \%$ of the respondents were workers in public universities whilst the remaining worked in private institutions.

Measurement model assessment: Schumacker and Lomax (2004), Hair et al. (2010) indicate that the two steps assessment procedure which includes measurement model and structural model has an advantage over the one step assessment procedure. According to Hair et al. (2017) measurement model specifies how each construct is measured while structural model specifies how the variables are related to each other in the structural model. The main reasons for choosing PLS as a statistical method for this study that for both measurement and structural model PLS offer simultaneous analysis which leads to more accurate estimates (Barclay et al., 1995).

The assessment of measurement model was done through construct reliability as well as validity (including convergent and discriminant validity). For construct reliability, this study tested the individual Cronbach's alpha coefficients to measure the reliability of each of the core variables in the measurement model. The results indicate that all the individual Cronbach's alpha coefficients ranging from 0.787-0.977 were higher than the suggested value of 0.7 (Kannan and Tan, 2005). Additionally, for testing construct reliability all the Composite Reliability (CR) values ranging from 0.899-0.978 were higher than 0.7 (Werts et al., 1974; Kline, 2010; Gefen et al., 2000) which adequately indicates that construct reliability is fulfilled as shown in Table 1. Therefore, the achieved Cronbach's alpha and CR for all constructs were considered to be sufficiently error-free.

Factor loading was used to test indicator reliability. High loadings on a construct indicate that the associated indicators seem to have much in common which is captured by the construct (Hair et al., 2017). Factor loadings $>0.50$ were considered to be very significant (Hair et al., 2010). The loadings for all items exceeded the recommended value of 0.5 as shown in Table 2 . The loading for all items in the model has therefore fulfilled all the requirements. 
J. Eng. Applied Sci., 15 (2): 714-729, 2020

Table 1: Summary of demographic profile of respondents

\begin{tabular}{lrr}
\hline Variables & Frequency & Valid (\%) \\
\hline Genders & 193 & \\
Male & 116 & 62.50 \\
Female & & 37.50 \\
Age & 95 & \\
$<30$ & 129 & 30.70 \\
$30-39$ & 66 & 41.70 \\
$40-49$ & 15 & 21.40 \\
$50-59$ & 4 & 4.90 \\
60 and above & & 1.30 \\
Experience & 78 & \\
$<5$ years & 56 & 25.30 \\
5-10 & 73 & 18.10 \\
$11-15$ & 54 & 23.60 \\
$16-20$ & 48 & 17.50 \\
More than 20 & & 15.50 \\
Academic position & 26 & \\
Teaching assistant & 82 & 8.40 \\
Lecturer & 168 & 26.50 \\
Assistant professor & 20 & 54.40 \\
Associate professor & 13 & 6.50 \\
Professor & & 4.20 \\
University & 71 & 22.98 \\
Public & 238 & 77.02 \\
Private & 309.00 & \\
Total & & \\
\hline
\end{tabular}

For testing convergent validity (the extent to which a measure correlates positively with alternative measures of the same construct, this study used the Average Variance Extracted (AVE) and it indicated that all AVE values were higher than the suggested value of 0.50 (Hair et al., 2010 ) ranging from $0.640-0.824$. The convergent validity for all constructs has been successfully fulfilled and adequate convergent validity exhibited as Table 2 shows.

The discriminant validity (the degree to which items differentiate among constructs or measure distinct concepts) of the measurement model was checked using three criteria, namely cross-loadings, Fornell-Larcker and the Heterotrait-Monotrait ratio (HTMT). According to (Hair et al., 2017), the cross-loadings are typically the first approach to assess discriminant validity of the indicators. As shown in Table 3 the cross loading criterion fulfills the requirements because the indicators outer loadings on a construct were higher than all its cross-loadings with other constructs (bold values).

The results of discriminant validity by using the Fornell-Larcker criterion is shown in Table 4 where the square root of the AVEs on the diagonals as represented by the bolded values are higher than the correlations between constructs (corresponding row and column values). This indicates that the constructs are strongly related to their respective indicators compared to other constructs of the model (Fornell and Larcker, 1981; Chin, 1998a, b), thus, suggesting a good discriminant validity
(Hair et al., 2017). In addition, the correlation between exogenous constructs is $<0.85$ (Awang, 2014). Hence, the discriminant validity of all constructs is fulfilled.

There has been some criticism of the Fornell-Larcker criterion, Henseler et al. (2015) mentioned that it does not accurately reveal the lack of discriminant validity in common research situations. They have proposed an alternative technique which is the Heterotrait-Monotrait ratio (HTMT) of correlations based on the multitrait multimethod matrix. This study assesses discriminant validity through HTMT. While the discriminant validity has a problem when the HTMT value is greater than HTMT 0.90 value of 0.90 (Gold et al., 2001) or the HTMT 0.85 value of 0.85 (Kline, 2010), all values as Table 5 shows were lower than the recommended value of 0.85 indicating that discriminant validity has been ascertained.

Structural model assessment: Hair et al. (2017) suggested assessing the structural model by looking at the beta $(\beta), \mathrm{R}^{2}$ and the corresponding t-values via. a bootstrapping procedure with a resample of 5, 000 . Moreover, they recommend reporting the effect sizes $\left(\mathrm{f}^{2}\right)$ as well as the predictive relevance $\left(\mathrm{Q}^{2}\right)$. As (Sullivan and Feinn, 2012) argue that the p-value determine whether the effect exists but it does not reveal the size of the effect.

Hypothesis tests: The structural model assessment as shown in Fig. 2 and Table 6 provides the indication of the hypothesis tests with 5 out of the 5 hypothesis are supported. SL significantly predicts OUP, INN and ESA. Hence, $\mathrm{H}_{1}, \mathrm{H}_{2}$ and $\mathrm{H}_{3}$ are ac cepted with $(\beta=0.605$, $\tau=8.984, \mathrm{p}<0.001), \beta=0.765, \tau=27.776, \mathrm{p}<0.001$ and $\beta=0.751, \tau=25.822, p<0.001$, respectively. In addition ESA and INN significantly predicts OUP. Hence, $\mathrm{H}_{4}$ and $\mathrm{H}_{5}$ are accepted with $(\beta=0.159, \tau=2.688, \mathrm{p}<0.01$ and $\beta=0.122, \tau=0.034, p<0.05$ ), respectively. Note that the standardized path coefficient indicates the strengths of the relationship between exogenous and endogenous constructs, so the direct effects of SP on OUP are much stronger than the influence of other variables. SP, ESA and INN are explaining $68.5 \%$ of the variance in OUP. The $\mathrm{R}^{2}$ values achieved an acceptable level of explanatory power as recommended by Cohen (1988) and Chin (1998a, b) indicating a substantial model.

This study also assessed effect sizes $\left(\mathrm{f}^{2}\right)$. Effect size $\mathrm{f}^{2}$ determines whether an exogenous latent construct has a substantial, moderate or weak impact on an endogenous latent construct (Gefen and Rigdon, 2011). Hair et al. (2017) recommend to test the change in the $\mathrm{R}^{2}$ value. 
J. Eng. Applied Sci., 15 (2): 714-729, 2020

Table 2: Mean, standard deviation, loading, Cronbach’s alpha, CR and AVE

\begin{tabular}{|c|c|c|c|c|c|c|c|}
\hline Constructs & Items & Loading $(>0.5)$ & $\mathrm{M}$ & SD & $\alpha(>0.7)$ & $\mathrm{CR}(>0.7)$ & $\operatorname{AVE}(>0.5)$ \\
\hline \multirow[t]{35}{*}{ Strategic planning (SL) } & EVL1 & 0.851 & & & & & \\
\hline & EVL2 & 0.748 & & & & & \\
\hline & EVL3 & 0.893 & & & & & \\
\hline & EVL4 & 0.919 & & & & & \\
\hline & EXT1 & 0.815 & & & & & \\
\hline & EXT2 & 0.891 & & & & & \\
\hline & EXT3 & 0.887 & & & & & \\
\hline & EXT4 & 0.812 & & & & & \\
\hline & EXT5 & 0.801 & & & & & \\
\hline & IMPL1 & 0.840 & & & & & \\
\hline & IMPL2 & 0.881 & & & & & \\
\hline & IMPL3 & 0.862 & & & & & \\
\hline & IMPL4 & 0.841 & & & & & \\
\hline & IMPL5 & 0.776 & & & & & \\
\hline & INTR1 & 0.881 & & & & & \\
\hline & INTR2 & 0.902 & & & & & \\
\hline & INTR4 & 0.881 & & & & & \\
\hline & INTR5 & 0.817 & & & & & \\
\hline & INTR6 & 0.876 & & & & & \\
\hline & MISS1 & 0.767 & 4.22 & 1.377 & 0.977 & 0.978 & 0.674 \\
\hline & MISS2 & 0.855 & & & & & \\
\hline & MISS3 & 0.860 & & & & & \\
\hline & MISS4 & 0.860 & & & & & \\
\hline & OBJ1 & 0.877 & & & & & \\
\hline & OBJ2 & 0.895 & & & & & \\
\hline & OBJ3 & 0.909 & & & & & \\
\hline & RES1 & 0.856 & & & & & \\
\hline & RES2 & 0.905 & & & & & \\
\hline & RES3 & 0.902 & & & & & \\
\hline & RES4 & 0.857 & & & & & \\
\hline & RES5 & 0.880 & & & & & \\
\hline & SP1 & 0.811 & & & & & \\
\hline & SP2 & 0.866 & & & & & \\
\hline & SP3 & 0.862 & & & & & \\
\hline & SP4 & 0.808 & & & & & \\
\hline \multirow[t]{9}{*}{ Innovation (INN) } & VIS1 & 0.870 & & & & & \\
\hline & VIS2 & 0.879 & & & & & \\
\hline & VIS3 & 0.874 & & & & & \\
\hline & VIS4 & 0.760 & & & & & \\
\hline & INN1 & 0.814 & & & & & \\
\hline & INN2 & 0.772 & & & & & \\
\hline & INN3 & 0.792 & 4.14 & 1.606 & 0.860 & 0.899 & 0.640 \\
\hline & INN4 & 0.814 & & & & & \\
\hline & INN5 & 0.809 & & & & & \\
\hline Employee Strategic & ESA1 & 0.913 & 4.12 & 1.661 & 0.787 & 0.904 & 0.824 \\
\hline Alignment (ESA) & ESA2 & 0.903 & & & & & \\
\hline University Operational & PERF1 & 0.679 & & & & & \\
\hline \multirow[t]{5}{*}{ Performance (UOP) } & PERF2 & 0.780 & & & & & \\
\hline & PERF3 & 0.870 & 4.33 & 1.594 & 0.857 & 0.903 & 0.701 \\
\hline & PERF4 & 0.878 & & & & & \\
\hline & PERF5 & 0.864 & & & & & \\
\hline & PERF6 & 0.784 & & & & & \\
\hline
\end{tabular}

M: Mean; SD: Standard Deviation, $\alpha$ : Cronbach's alpha, CR: Composite Reliability, AVE: Average variance extracted the measurement used is seven-point scale ranging from 1 (strongly disagree) to 7 (strongly agree) all the factor loadings of the individual items are statistically significant $(\mathrm{p}<0.01)$

Cohen (1988) suggested a guideline measure the magnitude of the $\mathrm{f}^{2}$ which is 0.35 (large effects), 0.15 (medium effects) and 0.02 (small effects). The result of $\mathrm{f}^{2}$ as Table 6 shows that three relationship with large effect sizes, two relationships with medium effect size and one relationship with small effect size. 
J. Eng. Applied Sci., 15 (2): 714-729, 2020

Table 3: Results of discriminant validity by the cross loading

\begin{tabular}{|c|c|c|c|c|}
\hline Variables & ESA & INN & PERF & SP \\
\hline$\overline{\text { EVL1 }}$ & 0.459 & 0.424 & 0.589 & 0.851 \\
\hline EVL2 & 0.392 & 0.536 & 0.597 & 0.748 \\
\hline EVL3 & 0.532 & 0.486 & 0.648 & 0.893 \\
\hline EVL4 & 0.563 & 0.528 & 0.638 & 0.919 \\
\hline EXT1 & 0.489 & 0.494 & 0.538 & 0.815 \\
\hline EXT2 & 0.490 & 0.537 & 0.537 & 0.891 \\
\hline EXT3 & 0.551 & 0.621 & 0.613 & 0.887 \\
\hline EXT4 & 0.410 & 0.625 & 0.545 & 0.812 \\
\hline EXT5 & 0.358 & 0.510 & 0.471 & 0.801 \\
\hline IMPL1 & 0.542 & 0.609 & 0.707 & 0.840 \\
\hline IMPL2 & 0.594 & 0.549 & 0.716 & 0.881 \\
\hline IMPL3 & 0.531 & 0.548 & 0.652 & 0.862 \\
\hline IMPL4 & 0.740 & 0.580 & 0.670 & 0.841 \\
\hline IMPL5 & 0.723 & 0.494 & 0.578 & 0.776 \\
\hline INTR1 & 0.562 & 0.541 & 0.634 & 0.881 \\
\hline INTR2 & 0.516 & 0.577 & 0.608 & 0.902 \\
\hline INTR4 & 0.542 & 0.563 & 0.606 & 0.881 \\
\hline INTR5 & 0.495 & 0.514 & 0.504 & 0.817 \\
\hline INTR6 & 0.511 & 0.440 & 0.548 & 0.876 \\
\hline MIS1 & 0.601 & 0.438 & 0.415 & 0.767 \\
\hline MIS2 & 0.420 & 0.487 & 0.483 & 0.855 \\
\hline MIS3 & 0.494 & 0.546 & 0.565 & 0.860 \\
\hline MIS4 & 0.478 & 0.635 & 0.600 & 0.860 \\
\hline RES1 & 0.601 & 0.587 & 0.595 & 0.856 \\
\hline RES2 & 0.541 & 0.656 & 0.571 & 0.905 \\
\hline RES3 & 0.524 & 0.665 & 0.489 & 0.902 \\
\hline RES4 & 0.514 & 0.578 & 0.646 & 0.857 \\
\hline RES5 & 0.499 & 0.568 & 0.659 & 0.880 \\
\hline OBJ1 & 0.500 & 0.529 & 0.540 & 0.877 \\
\hline OBJ2 & 0.403 & 0.408 & 0.428 & 0.895 \\
\hline OBJ3 & 0.432 & 0.394 & 0.443 & 0.909 \\
\hline SP1 & 0.493 & 0.508 & 0.479 & 0.811 \\
\hline SP2 & 0.474 & 0.443 & 0.443 & 0.866 \\
\hline SP3 & 0.472 & 0.486 & 0.454 & 0.862 \\
\hline SP4 & 0.496 & 0.528 & 0.514 & 0.808 \\
\hline VIS1 & 0.532 & 0.462 & 0.389 & 0.870 \\
\hline VIS2 & 0.470 & 0.474 & 0.366 & 0.879 \\
\hline VIS3 & 0.488 & 0.471 & 0.428 & 0.874 \\
\hline VIS4 & 0.428 & 0.480 & 0.417 & 0.760 \\
\hline ESA1 & 0.913 & 0.543 & 0.623 & 0.612 \\
\hline ESA2 & 0.903 & 0.534 & 0.622 & 0.651 \\
\hline INN1 & 0.520 & 0.814 & 0.617 & 0.662 \\
\hline INN2 & 0.374 & 0.772 & 0.463 & 0.548 \\
\hline INN3 & 0.506 & 0.792 & 0.496 & 0.602 \\
\hline INN4 & 0.412 & 0.814 & 0.502 & 0.597 \\
\hline INN5 & 0.539 & 0.809 & 0.612 & 0.638 \\
\hline PERF1 & 0.393 & 0.419 & 0.679 & 0.480 \\
\hline PERF2 & 0.554 & 0.534 & 0.780 & 0.611 \\
\hline PERF3 & 0.648 & 0.621 & 0.870 & 0.745 \\
\hline PERF4 & 0.597 & 0.590 & 0.878 & 0.721 \\
\hline PERF5 & 0.607 & 0.575 & 0.864 & 0.725 \\
\hline PERF6 & 0.502 & 0.539 & 0.784 & 0.656 \\
\hline
\end{tabular}

SP: Strategic Planning, ESA: Employee Strategic Alignment, IMPL: Strategy Implementation, SPF: Strategy Formalization, INTR: Internal Orientation, EXT: External Orientation, INN: Innovation, VIS: University Vision, MIS: University Mission, RES: Resources Provided, OBJ: Goals and Objectives, EVL: Strategic Planning Evaluation, PERF: University Operational Performance

Table 4: Results of discriminant validity by Fornell-Larcker criterion

\begin{tabular}{lcccc}
\hline Variables & ESA & INN & PERF & \\
\hline ESA & $\mathbf{0 . 9 0 8}$ & & & \\
INN & 0.593 & $\mathbf{0 . 8 0 0}$ & & \\
PERF & 0.685 & 0.678 & $\mathbf{0 . 8 1 2}$ & \\
SP & 0.551 & 0.565 & 0.617 & $\mathbf{0 . 8 8 0}$ \\
\hline
\end{tabular}

Diagonals represent the square root of the average variance extracted while the other entries represent the correlations SP: Strategic Planning,

ESA: Employee Strategic Alignment, INN: Innovation, PERF: University operational Performance 
Table 5: Results of discriminant validity by HTMT

\begin{tabular}{lccc}
\hline Variables & ESA & INN & PERF \\
\hline ESA & & & \\
INN & 0.714 & & \\
PERF & 0.808 & 0.761 & 0.649 \\
SP & 0.711 & 0.832 & - \\
\hline SP: Strategic Planning, ESA: Emlpyee Strategic Alignment, INN: Innovation, PERF: University operational Performance
\end{tabular}

SP: Strategic Planning, ESA: Emlpyee Strategic Alignment, INN: Innovation, PERF: University operational Performance

Table 6: Structural path analysis result

\begin{tabular}{|c|c|c|c|c|c|c|c|c|c|c|}
\hline Hypothesis & Relationship & SD Beta & SE & t-values & p-values & Decision & $\mathrm{R}^{2}$ & $\mathrm{f}^{2}$ & $\mathrm{Q}^{2}$ & VIF \\
\hline $\mathrm{H}_{1}$ & SP->PERF & 0.605 & 0.603 & 8.9840 & 0.000 & Supported & 0.685 & 0.323 & 0.419 & 2.666 \\
\hline $\mathrm{H}_{2}$ & SP->INN & 0.765 & 0.764 & 27.7760 & 0.000 & Supported & 0.585 & 1.408 & 0.348 & 1.000 \\
\hline $\mathrm{H}_{3}$ & SP->ESA & 0.751 & 0.750 & 25.8220 & 0.000 & Supported & 0.565 & 1.296 & 0.444 & 1.555 \\
\hline $\mathrm{H}_{4}$ & ESA->PERF & 0.159 & 0.158 & 2.6880 & 0.007 & Supported & 0.685 & 0.035 & & \\
\hline $\mathrm{H}_{5}$ & INN->PERF & 0.122 & 0.123 & 2.1280 & 0.034 & Supported & 0.685 & 0.020 & & \\
\hline
\end{tabular}

SP: Strategic Planning, ESA: Employee Strategic Alignment, INN: Innovation, PERF: University Operational Performance

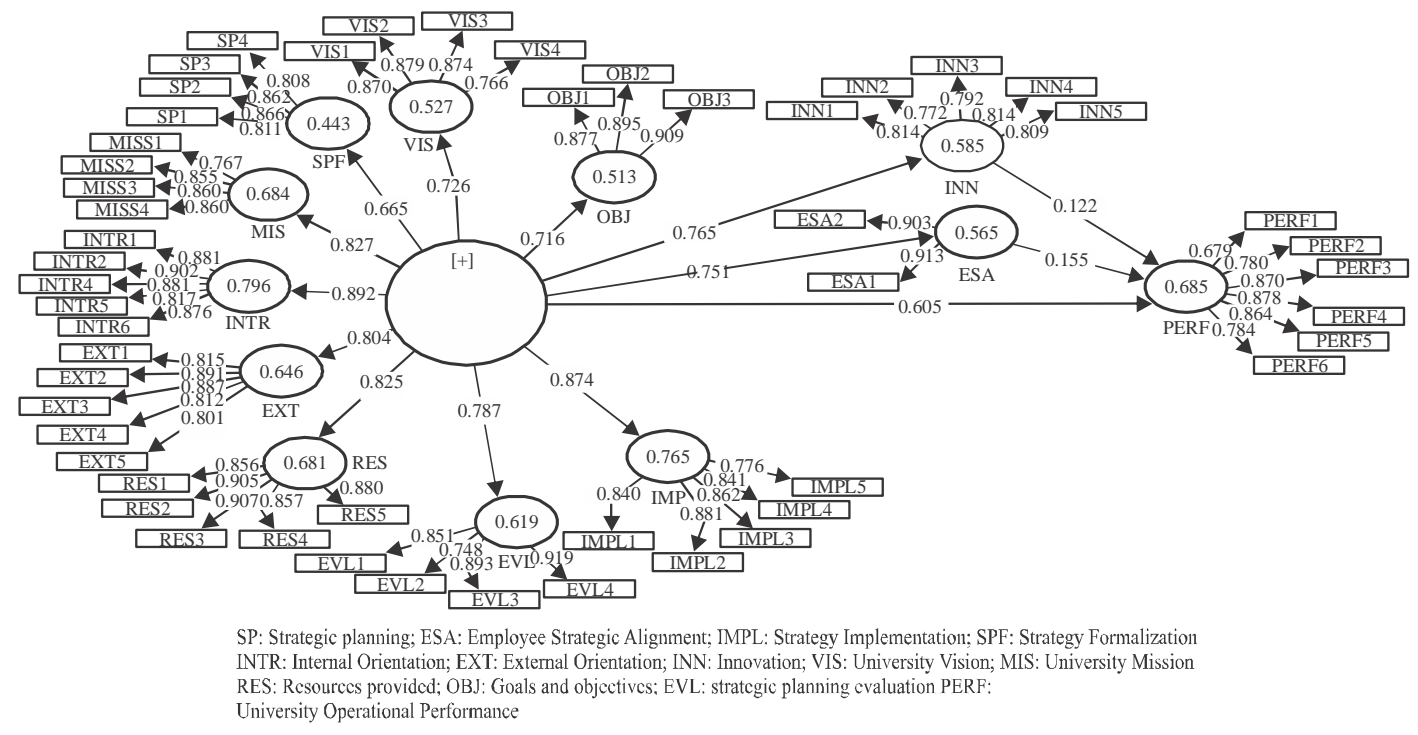

Fig. 2: PLS algorithm results

Further, by using the blindfolding procedure this study examined the power of research proposed model regarding the predictive relevance. As recommended by Hair et al. (2017) the blindfolding procedure should use only on the endogenous constructs with a reflective measurement. If the value of $\mathrm{Q}^{2}>0$ then the predictive relevance of the proposed model exists for a certain endogenous construct (Fornell and Cha, 1994; Hair et al., 2017). As Table 6 shows that all the values of $Q^{2}>0$ indicate that there is an adequate predictive relevance for the proposed model. For the $\mathrm{Q}^{2}$ values, Hair et al. (2017) suggested values of 0.35 (large), 0.15 (medium) and 0.02 (small) as a relative measure of predictive relevance and the result of this study shows that the exogenous have two large predictive relevance and one with medium predictive relevance.

An issue of the multicollinearity could exist in any study which is not desirable, it means that the variance exogenous constructs explain in the endogenous construct are overlapping with each other and thus not each explaining unique variance in the endogenous variable (O'Brien, 2007). To measure and assess the degree of multicollinearity, Variance Inflation Factor (VIF) widely used (O'Brien, 2007). There is cause for concern when the largest VIF is >10 (Bowerman and O'Connell, 1990; Myers, 1990). And according to Hair et al. (2017) a multicollinearity issue exists when the largest VIF is $>5$. Table 6 shows multicollinearity diagnostic through VIF which indicates that there is no evidence of significant multicollinearity among the study exogenous constructs because all VIF values are $<5$ ranging from $1.00-2.666$. It means that the variance of exogenous constructs explains in the endogenous construct are not overlapping with each other.

Indirect hypothesis testing: According to the bootstrapping's analysis, there is a significant indirect impact in the relationship between SP and OUP via. ESA 
J. Eng. Applied Sci., 15 (2): 714-729, 2020

Table 7: Bootstrapping the indirect effect of IM

\begin{tabular}{llcccrr}
\hline Hypothesis & Constructs & B-values & SE & t-values & p-values & Decision \\
\hline $\mathrm{H}_{6}$ & SP-> ESA->PERF & 0.119 & 0.119 & 2.679 & 0.008 & Supported \\
$\mathrm{H}_{7}$ & SP->INN->PERF & 0.093 & 0.094 & 2.126 & 0.034 & Supported \\
\hline SP: Strategic Planning, ESA: Employee Strategic Alignment, INN: Innovation, PERF: University Operational Performance (Preacher and Hayes, 2008)
\end{tabular}

Table 8: IPMA for UOP

\begin{tabular}{lcc}
\hline $\begin{array}{l}\text { Latent } \\
\text { constructs }\end{array}$ & $\begin{array}{c}\text { Total effect of the construct } \\
\text { operational performance (importance) }\end{array}$ & $\begin{array}{c}\text { Index values } \\
\text { (performance) }\end{array}$ \\
\hline ESA & 0.142 & 63.197 \\
INN & 0.119 & 58.664 \\
SP & 0.923 & 59.070 \\
\hline SP: Strategic Planning, ESA: Employee Strategic Alignment, INN: \\
Innovation
\end{tabular}

with a t-value of 2.679 and $\mathrm{p}<0.01$. as indicated by Preacher and Hayes (2008) that the mediation effect exist when the indirect impact of SP and OUP via. ESA with boot 95\% C1: [LL $=0.031$, UL $=0.206$ ] doesn't straddle a zero in between. Hence, $\mathrm{H}_{6}$ was supported. In addition the results showed there is a significant indirect impact in the relationship between SP and OUP via. INN with a t-value of 2.126 and $\mathrm{p}<0.05$ as indicated by Preacher and Hayes (2008) that the mediation effect exist when the indirect impact of SP and OUP via. INN with boot 95\% C1: [LL $=0.018$, UL $=0.184$ ] doesn't straddle a zero in between. Hence, $\mathrm{H}_{7}$ was supported (Table 7).

Importance-Performance Map Analysis (IPMA): This study ran an Importance-Performance Matrix Analysis (IPMA) as a post-hoc procedure in PLS using organizational performance as the outcome construct. The IPMA estimates the total effects represented by the importance of predecessor constructs in shaping the target construct (organizational performance) while their average latent variable scores represent their performance, the computation of the index values (performance scores) was accomplished by rescaling the latent constructs scores to a range of 100 (highest performance) down to 0 (lowest performance) (Hair et al., 2017). According to Ringle and Sarstedt (2016), IPMA enriches the PLS analysis results. Instead of only analyzing the path coefficients (i.e., the importance dimension), it also takes into consideration the average value of the latent constructs and their indicators (i.e., performance dimension). Table 8 shows the findings of importance (total effects) and performance (index values) used for the IPMA.

As shown in Fig. 3 this study plotted the total effects scores and index values in a priority map. It can be observed that $\mathrm{SP}$ is a very important factor in determining the UOP due to its relatively higher importance value compared to other constructs in the proposed model. Nevertheless, the performance of this Significant Factor (SP) lagged behind the INN and ESA. According to Hair et al. (2017) The goal of IPMA is to identify predecessors that have a relatively high importance for the target construct (i.e., those that have a strong total effect) but also a relatively low performance (i.e., low average latent variable scores), the aspects underlying these constructs represent potential areas of improvement that may receive high attention. In sum, in order to improve the UOP, the managerial activities should focus on enhancing the performance of SP.

According to the hypotheses result, this study model points out the outcomes in a separate relationship. The model has shown that strategic planning has positively and significantly influence university operational performance. Thus, the results have shown above if the strategic plan has strong appropriate elements for a future plan, the operational performance will be increased. This relationship has pointed out in the literature that strategic planning significantly impacts on operational performance (Miller and Cardinal, 1994). The results also indicated the factors of strategic planning that articulated the entire mission, vision, internal and external formulation, implementation that impose to connect university operational performance. Furthermore, innovation plays an important role in finding a result that it mediates between strategic planning and university operational performance (Urgal et al., 2013). This mediating effect significantly has supported both variables relationship in order to place innovative consequences with the organization. Innovation or innovative behavior in the organization creates a situation for new ideas that conclude strategic plans are framed (Leal-Rodriguez et al., 2014). On the other hand, the findings have shown that the innovation significantly influences university operational performance. The findings suggested that the innovation of the organization, generally, practice or involve with the staff will directly engage in operational performance (Damanpour and Evan, 1984). In general, innovative approaches are very much needed to the higher education system or universities operations. Its common in the relationship between innovation and operational performance according to the findings and many studies are investigated in the literature but the university and UAE context it very new of linked for innovation and operational performance.

Moreover, employee strategic alignment also plays a mediating role of strategic planning and university operational learning. The above result has shown the mediating of both variables significantly influenced and supported the indirect hypothesis. Chan et al. (1997) have discussed the investigated their implications for the effectiveness and business performance. The 


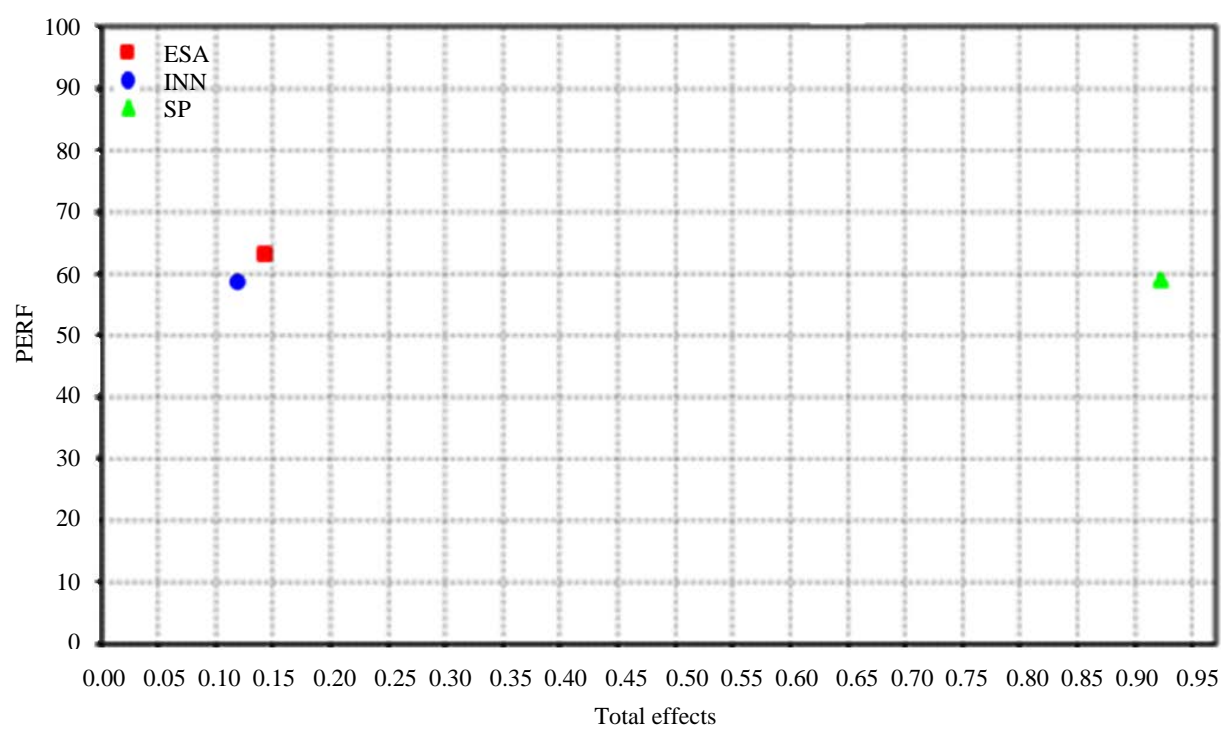

Fig. 3: IPMA (Priority Map) for employee performance, SP: Strategic Planning, ESA: Employee Strategic Alignment, INN: Innovation; PERF; University operational Performance

findings suggest the university with high strategic alignment are better performing in their operation. Although, the findings implied that there several ways to a win in order to state as no one strategic alignment and university operational performance was linked.

\section{CONCLUSION}

The findings were convinced to the point that we have developed in the practitioner-oriented version of the instruments to enable academic staff to assess and improve their operational performance as a direct influence.

\section{IMPLICATIONS}

This study has indicated two implications such as theoretical and managerial. Essentially, the study shows that the effects of SP and Innovation on UOP vary in local context. First, the theoretical implication that stands for relationships among the constructs which uttered for possible outcomes form the theoretical evidence. It indicates the result of the research that we identified of model constructs relationship-based contribution. There are an imposing variety of theoretical rationales to sustain the perspective that administrative settings provide a more fruitful venue for strategic planning relationships. Strategic planning implies the influence of operational performance in order to findings support we have outcomes form the results. This relationship theory supported in terms of the results of the mentioned hypothesis. Additionally, strategic planning significantly influences on university operational performance which mentioned from the extracted result. This relationship usually has considered in multi-cluster comparative research in order to evaluate strategically planned behavior (Rudd et al., 2008).

Moreover, strategic planning significantly influences on innovation that shows the positive relationship in terms of make the innovative culture of different employee appreciation. Consequently, innovation significantly influences university operational performance that criticized the common demonstration of being employee's innovation for better performance (Andersen, 2000). Besides, the indirect relationship or mediating influence between strategic planning and university operational performance also implement theoretical evidence to stand up this mediation effect. Luo and Park (2001) has considered the relationship of strategic alignment in groups within the organization. On the hand, strategic alignment influence on university operational performance. Furthermore, strategic alignment plays an important role between strategic planning and university operational performance in terms of interactions among their perception and conceptions regarding organizational performance. Therefore, the managerial implications comprise the observations made for making practical decisions to the organization. In this study, the theoretical implication observes the identifications to suggest for practical implantation and adapt to the strategies and workplace for future progression. Accordingly, relationship-based suggestions require providing indications such as strategic planning deploy the innovation and strategic alignment by increasing 
strategic plan and internal communication-based quality. On the hand strategic planning enhance university operational performance in order to develop planned behavior of the strategic goal. So, these findings suggest to the top management to imply the idea for reducing lacking and weaknesses of the organization and improve operational performance for future stability.

\section{LIMITATIONS}

Nonetheless, the results of this research should be interpreted cautiously. Perhaps a serious limitation of this study was its focus on a single industry, thus, precluding the generalization of findings to other industries including services and public sectors. The data were gathered from single respondents which might result in possible response bias. Future research should strive to gather data from firms across whole supply chains. Another shortcoming of this study is the lack of adequate sample size which hindered us to apply more rigorous statistical tests such as structural equation models. The study should be regarded as an exploratory study and be used as a basis for further deepened research with relatively large data sets. Therefore, future research may examine the proposed associations by incorporating contextual variables into the framework including industry type, supply chain structure, ownership type and intraregional variations to further probe into contingencies and boundary conditions of relationships examined in this study. Finally, there is a need for further conceptualization and verification of the factors used in this study, following two rigorous factor analyses. If these factors with the same practices hold in other research settings, it could be possible to proceed with further conceptualization and theorization around the identified factors and test new hypothesis empirically.

\section{REFERENCES}

Abd-Elaziz, M.E., W.M. Aziz, G.S. Khalifa and M. Abdel-Aleem, 2015. Determinants of Electronic Word of Mouth (EWOM) influence on hotel customers purchasing decision. Intl. J. Heritage Tourism Hospitality, 9: 194-223.

Abou-Shouk, M.A. and G.S. Khalifa, 2017. The influence of website quality dimensions on E-purchasing behaviour and E-loyalty: A comparative study of Egyptian travel agents and hotels. J. Travel Tourism Marketing, 34: 608-623.

Abou-Shouk, M.A., A.S. Abdelhakim and M.M. Hewedi, 2014. Factors affecting the development of target competencies among final-year tourism and hospitality students in Egypt. J. Hospitality Tourism Educ., 26: 178-187.

Acemoglu, D., U. Akcigit, H. Alp, N. Bloom and W. Kerr, 2018. Innovation, reallocation and growth. Am. Econ. Rev., 108: 3450-3491.
Ackoff, R., 1970. A concept of corporate planning. Long Range Plann., 3: 2-8.

Adams, R., J. Bessant and R. Phelps, 2006. Innovation management measurement: A review. Int. J. Manage. Rev., 8: 21-47.

Adi, H. and S. Pulos, 1980. Individual differences and formal operational performance of college students. J. Res. Math. Educ., 11: 150-156.

Agwa, Y., W. Aziz and G. Khalifa, 2018. Evaluating food and beverage courses in higher private tourism and hotels institutes in Alexandria: Professionals perception. Intl. J. Heritage Tourism Hospitality, 11: 98-110.

Albadry, H., 2015. The Effect of Pad Assisted Language Learning on Eveloping EFL Students Autonomous Language Learning. In: Critical CALL-Proceedings of the 2015 EUROCALL Conference, Helm, F., L. Bradley, M. Guarda and S. Thouesny (Eds.). Publishing Research, Padova, Italy, pp: 1-8.

Albadry, O.M., 2016. Strategic management and its impact on universities service quality: The role of organisational commitment. Masters Thesis, University Plymouth, Plymouth, UK.

Alkhateri, A.S., A.E. Abuelhassan, G.S. Khalifa, M. Nusar and A. Ameen, 2018. The impact of perceived supervisor support on employees turnover intention: The mediating role of job satisfaction and affective organizational commitment. Intl. Bus. Manage., 12: 477-492.

Andersen, T.J., 2000. Strategic planning, autonomous actions and corporate performance. Long Range Plann., 33: 184-2000.

Antony, J.P. and S. Bhattacharyya, 2010. Measuring organizational performance and organizational excellence of SMEs-Part 1: A conceptual framework. Measuring Bus. Excellence, 14: 3-11.

Aragon-Correa, J.A., V.J. Garcia-Morales and E. Cordon-Pozo, 2007. Leadership and organizational learning's role on innovation and performance: Lessons from Spain. Ind. Marketing Manage., 36: 349-359.

Awang, Z., 2014. Structural Equation Modeling using AMOS. Universiti Teknologi MARA, Shah Alam, Malaysia,.

Badran, N. and G. Khalifa, 2016. Diversity management: Is it an important issue in hotel industry in Egypt?. Intl. J. Heritage Tourism Hospitality, 7: 275-286.

Barclay, D., C. Higgins and R. Thompson, 1995. The Partial Least Squares (PLS) approach to causal modeling: Personal computer adoption and use as an illustration. Technol. Stud., 2: 285-309.

Barney, J.B., 1991. Firm resources and sustained competitive advantage. J. Manage., 17: 99-120. 
Bason, C., 2018. Leading Public Sector Innovation: Co-Creating for a Better Society. 2nd Edn., Policy Press, University of Bristol, Bristol, England, Pages: 336.

Beehr, T.A., S. Glazer, R. Fischer, L.L. Linton and C.P. Hansen, 2009. Antecedents for achievement of alignment in organizations. J. Occup. Organiz. Psychol., 82: 1-20.

Berry, F.S. and W.D. Berry, 2007. Innovation and Diusion Models in Policy Research. In: Theories of the Policy Process, Sabatier, P.A. (Ed.). Westview Press, Boulder, Colorado, USA., ISBN-13:978-0-8133-4359-4, pp: 223-260.

Borman, W.C. and S.J. Motowidlo, 1993. Expanding the Criterion Domain to Include Elements of Contextual Performance. Jossey-Bass Publisher, San Fransisco.

Borrego, M. and C. Henderson, 2014. Increasing the use of evidence-based teaching in STEM higher education: A comparison of eight change strategies. J. Eng. Educ., 103: 220-252.

Boswell, W.R. and J.W. Boudreau, 2001. How leading companies create, measure and achieve strategic results through line of sight. Manage. Decis., 39: 851-860.

Bowen, J.T. and S. Shoemaker, 2003. Loyalty: A strategic commitment. Cornell Hotel Restaurant Administration Q., 44: 31-46.

Bowerman, B.L. and R.T. O'Connell, 1990. Linear Statistical Models: An Applied Approach. 2nd Edn., PWS-Kent Pub. Co., New York, USA., ISBN:9780534229856, Pages: 1024.

Brown, S.L. and K.M. Eisenhardt, 1995. Product development: Past research, present findings and future directions. Acad. Manage. Rev., 20: 343-378.

Celine, D., B. Fabrizio, M. Gabriel and Q. Alain, 2009. Too complex for me why do performance-approach and performance-avoidance goals predict exam performance?. Eur. J. Psychol. Educ., 24: 423-434.

Chan, Y.E., S.L. Huff, D.W. Barclay and D.G. Copeland, 1997. Business strategic orientation, information systems strategic orientation and strategic alignment. Inf. Syst. Res., 8: 125-150.

Chen, C.J. and Y.F. Huang, 2010. Creative workforce density, organizational slack, and innovation performance. J. Bus. Res., 63: 411-417.

Chin, W., 1998. The Partial Least Squares Approach for Structural Equation Modeling. In: Modern Methods for Business Research, Marcoulides, G.A. (Ed.). Lawrence Erlbaum Associates, New Jersey, pp: 295-336.

Chin, W.W., 1998. Commentary: Issues and opinion on structural equation modeling. MIS Q., 22: 7-16.
Cohen, J., 1988. Statistical Power Analysis for the Behavioral Sciences. 2nd Edn., Lawrence Erlbaum Associates, Hillsdale, New Jersey.

Conway, S. and F. Steward, 2009. Managing and Shaping Innovation. Oxford University Press, Oxford, USA., ISBN:9780199262267, Pages: 504.

Croom, S., N. Vidal, W. Spetic, D. Marshall and L. McCarthy, 2018. Impact of social sustainability orientation and supply chain practices on operational performance. Intl. J. Oper. Prod. Manage., 38: 2344-2366.

Damanpour, F. and W.M. Evan, 1984. Organizational innovation and performance: The problem of organizational lag. Admin. Sci. Q., 29: 392-409.

Dodgson, M., 2018. Technological Collaboration in Industry: Strategy, Policy and Internationalization in Innovation. Taylor \& Francis, Abingdon, UK., ISBN:9781351265584, Pages: 206.

Drucker, P., 2014. Innovation and Entrepreneurship. 1st Edn., Routledge, Abingdon, UK., ISBN-13:9781138019195, Pages: 346.

Feng, M., W. Yu, X. Wang, C.Y. Wong and M. Xu et al., 2018. Green supply chain management and financial performance: The mediating roles of operational and environmental performance. Bus. Strategy Environ., 27: 811-824.

Flynn, L.R. and D. Pearcy, 2001. Four subtle sins in scale development: Some suggestions for strengthening the current paradigm. Intl. J. Market Res., 43: 1-14.

Fornell, C. and D.F. Larcker, 1981. Evaluating structural equation models with unobservable variables and measurement error. J. Market. Res., 18: 39-50.

Fornell, C. and J. Cha, 1994. Partial Least Squares. In: Advanced Methods of Marketing Research, Bagozzi, R.P. (Ed.). Blackwell Business, Cambridge, Massachusetts, pp: 52-78.

Gagnon, M.A. and J.H. Judd, 2003. Employee strategic alignment at a wood manufacturer: An exploratory analysis using lean manufacturing. For. Prod. J., 53: 24-29.

Galbreath, J., 2010. Drivers of corporate social responsibility: The role of formal strategic planning and firm culture. Br. J. Manage., 21: 511-525.

Garcia-Morales, V.J., M.M. Jimenez-Barrionuevo and L. Gutierrez-Gutierrez, 2012. Transformational leadership influence on organizational performance through organizational learning and innovation. J. Bus. Res., 65: 1040-1050.

Gefen, D. and E.E. Rigdon, 2011. An update and extension to SEM guidelines for administrative and social science research. MIS. Q., 35: 1-7. 
Gefen, D., D.W. Straub and M.C. Boudreau, 2000. Structural equation modeling and regression: Guidelines for research practice. Commun. Assoc. Inform. Syst., 4: 1-77.

Gold, A.H., A. Malhotra and A.H. Segars, 2001. Knowledge management: An organizational capabilities perspective. J. Manage. Inform. Syst., 18: 185-214.

Hair, J.F., W.C. Black, B.J. Babin and R.E. Anderson, 2010. Multivariate Data Analysis: A Global Perspective. 7th Edn., Pearson Education Limited, Upper Saddle River, New Jersey, ISBN-13: 9780135153093, Pages: 800.

Hair, J.F., W.C. Black, B.J. Babin, R.E. Anderson and R.L. Tatham, 2006. Multivariate Data Analysis. 6th Edn., Pearson, London, UK., ISBN:9788131715284, Pages: 925.

Hair, Jr., J.F., G.T.M. Hult, C.M. Ringle and M. Sarstedt, 2017. A Primer on Partial Least Squares Structural Equation Modeling (PLS-SEM). 2nd Edn., Sage Publisher, Thousand Oaks, California.

Henderson, J.C. and H. Venkatraman, 1999. Strategic alignment: Leveraging information technology for transforming organizations. IBM Syst. J., 38: 472-484.

Henseler, J., C.M. Ringle and M. Sarstedt, 2015. A new criterion for assesing discriminant validity in variance-based structural equation modeling. J. Acade. Marketing Sci., 43: 115-135.

Hulland, J., 1999. Use of Partial Least Squares (PLS) in strategic management research: A review of four recent studies. Strat. Manage. J., 20: 195-204.

Hult, G.T.M., D.J. Ketchen Jr., S.T. Cavusgil and R.J. Calantone, 2006. Knowledge as a strategic resource in supply chains. J. Operat. Manage., 24: 458-475.

Hussein, I.E., M.A. Abou-Shouk and G.S. Khalifa, 2013. Evaluating tourism and hospitality graduates: Perceptions of stakeholders in Egypt. Proceedings of the 3rd Regional Conference on Tourism Research, October 29-31, 2013, Bayview Hotel, Langkawi, Malaysia, pp: 764-774.

Inman, R.A., R.S. Sale, K.W. Green and D. Whitten, 2011. Agile manufacturing: Relation to JIT, operational performance and firm performance. J. Oper. Manage., 29: 343-355.

Isaac, O., Y. Masoud, S. Samad and Z. Abdullah, 2016. The mediating effect of strategic implementation between strategy formulation and organizational performance within government institutions in Yemen. Res. J. Appl. Sci., 11: 1002-1013.

Jansen, J.J.P., F.A.J. Van Den Bosch and H.W. Volberda, 2006. Exploratory innovation, exploitative innovation and performance: Effects of organizational antecedents and environmental moderators. Manage. Sci., 52: 1661-1674.
Jimenez-Jimenez, D. and R. Sanz-Valle, 2011. Innovation, organizational learning and performance. J. Bus. Res., 64: 408-417.

Johnes, J., 1996. Performance assessment in higher education in Britain. Eur. J. Oper. Res., 89: 18-33.

Kannan, V.R. and K.C. Tan, 2005. Just in time, total quality management and supply chain management: Understanding their linkages and impact on business performance. Omega, 33: 153-162.

Ketokivi, M. and X. Castaner, 2004. Strategic planning as an integrative device. Administrative Sci. Q., 49: 337-365.

Kettunen, J., 2006. Strategic planning of regional development in higher education. Baltic J. Manage., 1: 259-269.

Kezar, A., A.C. Chambers, J.C. Burkhardt, 2015. Higher Education for the Public Good: Emerging Voices from a National Movement. Wiley, Hoboken, New Jersey, USA., ISBM:9781119177951, Pages: 384.

Khadem, R., 2008. Alignment and follow-up: Steps to strategy execution. J. Bus. Strategy, 29: 29-35.

Khalefa, G.S.A., 2015. Ethnic restaurants meal experience: Egyptian customers perceptions. Intl. J. Heritage Tourism Hospitality, 9: 93-112.

Khalifa, G.S. and E.H.A. Mewad, 2017. Managing drivers and boundaries of Information Technology Risk Management (ITRM) to increase Egyptian hotels market share. Intl. J. Recent Trends Bus. Tourism, 1: 12-31.

Khalifa, G.S. and M.A. Abou-Shouk, 2014. Investigating the success factors of hotel websites: The case of Egyptian hotels. Asia Pac. J. Innovation Hospitality Tourism, 3: 131-151.

Khalifa, G.S.A. and M. Hewedi, 2016. Factors affecting hotel website purchasing intentions: Evidence from Egypt. J. Faculty Tourism Hotels, Fayoum Univ., 8: 50-69.

Khalifa, G.S.A. and N.M. Fawzy, 2017. Measuring E-service quality (Expectation vs. perception) from travel agencies perspective: An empirical study on egyptian hotel websites. Intl. J. Recent Trends Bus. Tourism (IJRTBT), 1: 36-48.

Kleinberg, J.M., R. Kumar, P. Raghavan, S. Rajagopalan and A.S. Tomkins, 1999. The web as a graph: Measurements, models and methods. Proceedings of the International Conference on Computing and Combinatorics (COCOON 1999), July 26-28, 1999, Springer, Berlin, Heidelberg, Germany, ISBN:978-3-540-66200-6, pp: 1-17.

Kline, R.B., 2010. Principle and Practice of Structural Equation Modeling. 3rd Edn., Guilford Press, New York, ISBN: 9781606238776, Pages: 427. 
Kruss, G., S. McGrath, I.H. Petersen and M. Gastrow, 2015. Higher education and economic development: The importance of building technological capabilities. Intl. J. Educ. Dev., 43: 22-31.

Langly, A., 1988. The roles of formal strategic planning. Long Range Plann., 21: 40-50.

Lannelongue, G., J. Gonzalez-Benito and O. Gonzalez-Benito, 2015. Input, output and environmental management productivity: Effects on firm performance. Bus. Strategy Environ., 24: 145-158.

Latorre-Medina, M.J. and F.J. Blanco-Encomienda, 2013. Strategic management as key to improve the quality of education. Procedia Soc. Behav. Sci., 81: 270-274.

Leal-Rodriguez, A.L., J.A. Ariza-Montes, J.L. Roldan and A.G. Leal-Millan, 2014. Absorptive capacity, innovation and cultural barriers: A conditional mediation model. J. Bus. Res., 67: 763-768.

Leigh, N.G. and E.J. Blakely, 2016. Planning Local Economic Development: Theory and Practice. 6th Edn., SAGE Publications, Thousand Oaks, California, USA., ISBN:9781506364001, Pages: 536.

Luo, Y. and S.H. Park, 2001. Strategic alignment and performance of market-seeking MNCs in China. Strategic Manage. J., 22: 141-155.

Lusch, R.F. and S. Nambisan, 2015. Service innovation: A service-dominant logic perspective. MIS. Q., 39: $155-176$.

Malhotra, N.K., S.S. Kim and J. Agarwal, 2004. Internet users information privacy concerns (IUIPC): The construct, the scale and a causal model. Inf. Syst. Res., 15: 336-355.

Menon, A., S.G. Bharadwaj, P.T. Adidam and S.W. Edison, 1999. Antecedents and consequences of marketing strategy making: A model and a test. J. Marketing, 63: 18-40.

Miller, C.C. and L.B. Cardinal, 1994. Strategic planning and firm performance a synthesis of more than two decades or research. Acad. Manage. J., 37: 1649-1665.

Mohamed, M.S., G.S.A. Khalifa, A.H. Al-Shibami, I. Alrajawi and O. Isaac, 2019. The mediation effect of innovation on the relationship between creativity and organizational productivity: An empirical study within public sector organizations in the UAE. J. Eng. Appl. Sci., 14: 3234-3242.

Mohamed, M.S., G.S.A. Khalifa, M. Nusari, A. Ameen and A.H. Al-Shibami et al., 2018. Effect of organizational excellence and employee performance on organizational productivity within healthcare sector in the UAE. J. Eng. Appl. Sci., 13: 6199-6210.
Montoya-Weiss, M.M. and R.J. Calantone, 1994. Determinants of new product performance: A review and meta analysis. J. Prod. Innovation Manage., 11: 397-417.

Myers, R.H., 1990. Classical and Modern Regression with Applications. 2nd Edn., Duxbury, Washington.

Nusari, M., M. Al Falasi, I. Alrajawy, G.S. Khalifa and O. Isaac, 2018. The impact of project management assets and organizational culture on employee performance. Intl. J. Manage. Hum. Sci., 2: 15-26.

O’Brien, R.M., 2007. A caution regarding rules of thumb for variance inflation factors. Qual. Quantity, 41: 673-690.

Ouakouak, M.L. and N. Ouedraogo, 2013. The mediating role of employee strategic alignment in the relationship between rational strategic planning and firm performance: A European study. Can. J. Administrative Sci. Rev. Canadienne Sci. Administration, 30: 143-158.

O’Reilly, C.A., D.F. Caldwell, J.A. Chatman, M. Lapiz and W. Self, 2010. How leadership matters: The effects of leaders alignment on strategy implementation. Leadersh. Q., 21: 104-113.

Peterson, S.J., F. Luthans, B.J. Avolio, F.O. Walumbwa and Z. Zhang, 2011. Psychological capital and employee performance: A latent growth modeling approach. Personnel Psychol., 64: 427-450.

Prager, D.J. and G.S. Omenn, 1980. Research, innovation and university-industry linkages. Sci., 207: 379-384.

Prajogo, D.I., 2016. The strategic fit between innovation strategies and business environment in delivering business performance. Intl. J. Prod. Econ., 171: 241-249.

Preacher, K.J. and A.F. Hayes, 2008. Asymptotic and resampling strategies for assessing and comparing indirect effects in multiple mediator models. Behav. Res. Methods, 40: 879-891.

Qoura, O. and G.S.A. Khalifa, 2016. The impact of reputation management on hotel image among internal customers: The case of egyptian hotels. Intl. J. Heritage Tourism Hospitality, 7: 261-274.

Radomska, J., 2014. Linking the main obstacles to the strategy implementation with the companys performance. Procedia Soc. Behav. Sci., 150: 263-270.

Ringle, C.M. and M. Sarstedt, 2016. Gain more insight from your PLS-SEM results: The importance-performance map analysis. Ind. Manage. Data Syst., 116: 1865-1886.

Rolstadas, A., 1998. Enterprise performance measurement. Intl. J. Oper. Prod. Manage., 18: 989-999. 
Rudd, J.M., G.E. Greenley, A.T. Beatson and I.N. Lings, 2008. Strategic planning and performance: Extending the debate. J. Bus. Res., 61: 99-108.

Saunila, M., S. Pekkola and J. Ukko, 2014. The relationship between innovation capability and performance: The moderating effect of measurement. Int. J. Prod. Perform. Manage., 63: 234-249.

Schumacker, R.E. and R.G. Lomax, 2004. A Beginner's Guide to Structural Equation Modeling. 2nd Edn., Lawrence Erlbaum Associates, New Jersey, USA., ISBN:0-8058-4017-6,.

Shamsi, R.S.H.A., A.A. Ameen, O. Isaac, A.H. Al-Shibami and G.S. Khalifa, 2018. The impact of innovation and smart government on happiness: Proposing conceptual framework. Intl. J. Manage. Hum. Sci., 2: 10-26.

Shrader, C.B., L.A. Taylor and D.R. Dalton, 1984. Strategic planning and organizational performanceb critical appraisal. J. Manage., 10: 149-171.

Spee, A.P. and P. Jarzabkowski, 2011. Strategic planning as communicative process. Organ. Stud., 32: 1217-1245.

Sullivan, G.M. and R. Feinn, 2012. Using effect size-or why the $\mathrm{P}$ value is not enough. J. Graduate Med. Educ., 4: 279-282.

Tangen, S., 2003. An overview of frequently used performance measures. Work Study, 52: 347-354.

Uluskan, M., A.B. Godfrey and J.A. Joines, 2017. Integration of six sigma to traditional quality management theory: An empirical study on organisational performance. Total Qual. Manage. Bus. Excellence, 28: 1526-1543.
Urabe, K., J. Child and T. Kagono, 2018. Innovation and Management: International Comparisons. Walter de Gruyter, Berlin, Germany, Pages: 372.

Urgal, B., M.A. Quintas and R. Arevalo-Tome, 2013. Knowledge resources and innovation performance: The mediation of innovation capability moderated by management commitment. Technol. Anal. Strategic Manage., 25: 543-565.

Valdez, G., 2017. Intermediate manager experience: Implications for operational performance within veterinary clinical institutions. Ph.D Thesis, Argosy University Atlanta, Atlanta, USA.

Werts, C.E., R.L. Linn and K.G. Joreskog, 1974. Intraclass reliability estimates: Testing structural assumptions. Educ. Psychol. Meas., 34: 25-33.

Williams, J.C., 1988. A data-based method for assessing and reducing human error to improve operational performance. Proceedings of the Record for 1988 IEEE 4th International Conference on Human Factors and Power Plants, June 5-9, 1988, IEEE, Monterey, California, USA., pp: 436-450.

Woodside, A.G. and W.G. Biemans, 2005. Modeling innovation, manufacturing, diffusion and adoption/rejection processes. J. Bus. Ind. Marketing, 20: 380-393.

Wooldridge, B. and S.W. Floyd, 1990. The strategy process, middle management involvement and organizational performance. Strategic Manage. J., 11: 231-241. 